\title{
Criminalistic it Needs to be Understood as a Professional
}

\section{Career}

\author{
Manrique JIT* \\ Legal Consultant, Peru
}

*Corresponding author: Jorge Isaac Torres Manrique, Legal Consultant, Peru, Email:

\section{Investigation Paper}

Volume 3 Issue 2

Received Date: October 08, 2018

Published Date: October 12, 2018

DOI: $10.23880 /$ ijfsc-16000139

\section{Investigation Paper}

The criminalistic is the forensic science that studies crime as human and social behavior, investigates the causes of crime, the prevention of crime and the treatment of the offender. Carrying out such activities at the level of the administration of justice, the penitentiary field and the prevention of crime.

The criminalistic had its quasi-scientific appearance in China (650-identification of the finger pads in cave paintings of porcelain), however, began its scientific stage proper in France (1823- study on the disología and the cutaneous organ) and later in India (1893- study in identification and fingerprint).

In the Peruvian State the criminalistic (despite its nature of auxiliary and autonomous science) is developed at the level of the police institution (Division of Criminalistic of the National Police of Perú), basically in the rank of technician or expert. However, its scientific function, of rigorous study and investigation, acquires more and more importance, importance and transcendence.

The criminalistic in Peru, is only studied as a subject (and not as a professional career) scarcely at the level of pre-degree or law faculties, so too, the same happens at the master's level (in criminalistic law, for example); except for the master's degree in criminalistic. That is to say, a curricular (study, research and analysis) and scientific limitation is imposed on him. Forgetting that the nature of criminalistic studies is identifying, qualitative, quantitative and comparative; all this without neglecting strict methodological, technological and scientific observance.
In addition, we must consider the limited current exercise of criminalistic operators (without intending to demean it, rather, to improve it), as we believe it would be more appropriate to authorize their exercise but at a professional level, that is, after having studied the race university of criminalistics and obtained a professional title of the same.

The present investigation is justified: i) in the very nature (scientific, autonomous, broad, deep and professional) that presents the criminalistic. Given the inadequate exercise of the same in Peru, without having a respective professional title that authorizes such purpose. ii) and in the urgent and urgent need to improve the Peruvian criminalistic jurisdictional system in the specific subject of the "potentialization and development of the analysis, investigation, discovery and scientific verification of the alleged crime and the alleged offender" (which is nothing else that the improvement of the important task of preserving the scene of a crime to obtain and properly process the information that this provides us to be able to know the facts and present evidence regarding its execution, development and consummation).

It should be noted, however, that the present proposal implies unavoidably: i) analyzing the curricular plan of the criminalistic subjects of the law faculties; ii) of the subjects of criminalistic of the study centers of the National Police of Peru; iii) of the subjects of criminalistic and related of the masters in criminalistic; iv) of the criminalistic subjects of the masters in criminal law. v) analyze the graduate profile of the same and compare it with the necessary or optimal profile. Likewise, it also implies, vi) to determine the degree of necessity of the 


\section{International Journal of Forensic Sciences}

professionalization of criminalistic (read, creation of university faculties of criminalistic) regarding the level of topics, studies, research and analysis of universities, institutes and study centers that They give studies or training on criminalistic.

The criminalistic presents an amplitude and dizzying development at all levels that cannot be ignored or postponed, a fact for which we consider that our country has the unavoidable need to professionalize it, that is, to recognize it and grant it its true place. In this sense, we are of the opinion because criminalistic is studied, but, as a professional university career, granting a university degree of "criminalistics" to those who are entitled to it.
Finally, we consider (above all, in these times in which our reality presents an increasing crime rate and in which the Public Ministry and the National Police battle to obtain their respective criminalistic laboratories), that the implantation and validity of the professionalization and scientificity of criminalistic will decisively improve the study, analysis, development, research and function of it; contributing in turn to potentialize it for the benefit of investigating the scene of the crime -that is, in obtaining better answers or more exhaustive explanations to the "Golden Questions of Criminalistic" (such as: what?, where?, how?, when?, ¿who?, and ¿with what?)-

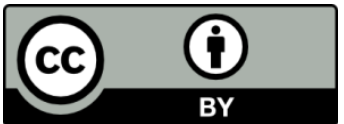

